\title{
The Concept of Equivalence in the Age of Translation Technology
}

\author{
Uliana, E. \\ Centre for Multidisciplinary \& Intercultural Inquiry, Centre for Translation Studies \\ University College London, London, United Kingdom
}

\begin{abstract}
The activity of terminology management and the concept of equivalence offer different insights into the nature of meaning and how words in different languages correspond to each other. This study analyses the challenges posed by high-end technology, particular the management of terminological data, in relation to the notion of equivalence. The author argues that recent translation technology is in dialectic with current developments in translation theory, approaches which displace the notion of meaning in translation away from the idea of equivalence. In addition, the paper suggests that if the concept of equivalence is to have any relevance in translation theory and practice today, a more encompassing approach needs to be embraced, one which considers a diversity of factors, both internal and external to language.
\end{abstract}

Keywords: difference, directional equivalence, equivalence, natural equivalence, semantic correspondence, terminology management, translation theory

Cite as: Uliana, E. (2018). The Concept of Equivalence in the Age of Translation Technology. Arab World English Journal for Translation \& Literary Studies, 2 (2).

DOI: http://dx.doi.org/10.24093/awejtls/vol2no2.16 